\title{
Aberrant Integrin Expression during Epidermal Wound Healing and in Psoriatic Epidermis
}

\author{
Mark D. Hertle, M.-Dominique Kubler, Irene M. Leigh, ${ }^{\star}$ and Fiona M. Watt \\ Keratinocyte Laboratory, Imperial Cancer Research Fund, London WC2A 3PX; and * Imperial Cancer Research Fund \\ Experimental Dermatology Group, Royal London Hospital, London E1 1BB, United Kingdom
}

\begin{abstract}
We have examined integrin expression during the remodeling of the epidermis that takes place during wound healing, using a suction blister model in which the epidermis is detached from the dermis, leaving the basement membrane intact. By immunofluorescence microscopy, we found that the same integrin subunits were expressed during wound healing as in normal epidermis with very little change in the relative intensity or distribution of staining at the leading edge of the migrating epidermis. However, at the time of wound closure, when the epidermis is still hyperproliferative, $\alpha_{2}, \alpha_{3}, \alpha_{6}$, and $\beta_{1}$ were no longer confined to the basal layer, as in normal epidermis, but were also found in all the living suprabasal cell layers, coexpressed with the terminal differentiation markers involucrin, keratin 10, and keratin 16. Strong suprabasal staining for $\alpha_{v}$ was also found in one specimen. $\beta_{4}$, which normally forms a heterodimer with $\alpha_{6}$, and $\alpha_{5}$ remained predominantly basal. Three of the integrin ligands, fibronectin, type IV collagen, and laminin, remained largely confined to the basement membrane zone and dermis. By $14 \mathrm{~d}$ after wounding, the integrins were once more restricted to the basal layer. Suprabasal integrin expression was also observed in involved psoriatic lesions. Thus, in two situations in which the epidermis is hyperproliferative, there is a failure to downregulate integrin expression on initiation of terminal differentiation. The functional consequences of this aberrant integrin expression remain to be explored. (J. Clin. Invest. 1992. 89:1892-1901.) Key words: hyperproliferation • extracellular matrix • cell migration • terminal differentiation • keratinocytes
\end{abstract}

\section{Introduction}

The integrins are a family of cell surface receptors that mediate cell-cell and cell-extracellular matrix adhesion (1-3). Integrins are heterodimers of one $\alpha$ and one $\beta$ subunit, each of which is a transmembrane glycoprotein. In human epidermis and stratified keratinocyte cultures, integrin expression is largely confined to the basal layer: keratinocytes express $\alpha_{1} \beta_{1}, \alpha_{2} \beta_{1}, \alpha_{3} \beta_{1}$, $\alpha_{5} \beta_{1}, \alpha_{6} \beta_{4}$, and $\alpha_{v} \beta_{5}(4-10) . \alpha_{1} \beta_{1}$ is only weakly detected in epidermis and is not seen consistently in culture; the keratinocyte $\alpha_{1} \beta_{1}$ ligand is unknown $(7,8)$. In cultured keratinocytes,

Address correspondence and reprint requests to Dr. Fiona M. Watt, Keratinocyte Laboratory, Imperial Cancer Research Fund, P.O. Box 123, Lincoln's Inn Fields, London WC2A 3PX, UK.

Received for publication 25 October 1991 and in revised form 30 January 1992.

J. Clin. Invest.

(c) The American Society for Clinical Investigation, Inc. $0021-9738 / 92 / 06 / 1892 / 10 \$ 2.00$

Volume 89, June 1992, 1892-1901 $\alpha_{2} \beta_{1}$ and $\alpha_{3} \beta_{1}$ have variously been reported to mediate adhesion to collagen and laminin; $\alpha_{5} \beta_{1}$ is a fibronectin receptor and $\alpha_{v} \beta_{5}$ is a vitronectin receptor $(8,9,11,12)$. Although the ligand for $\alpha_{6} \beta_{4}$ remains to be identified, this integrin is a component of hemidesmosomes $(13,14)$. Experiments with cultured keratinocytes suggest that integrins not only play a role in adhesion to the extracellular matrix (ECM), but also in cell-cell adhesion $(11,15)$ and in the initiation of terminal differentiation (16). During epidermal development there are major changes in the abundance and distribution of individual integrin subunits, providing indirect evidence for a role in establishing the spatial organization of keratinocytes in the epidermis (7).

In view of the evidence that integrins can regulate keratinocyte adhesion and terminal differentiation, we were interested to discover what happens to integrin expression when the epidermis is reformed after wounding. During wound healing, proliferation and lateral migration of keratinocytes are stimulated and the cells synthesize and respond to a range of inflammatory cytokines (17-19). The wound model we chose is that of reepithelialization following suction blister formation (20-22). Application of vacuum to a small area of skin causes a blister to form, in which the epidermis detaches from the dermis, but the basement membrane remains essentially intact. Keratinocytes migrate laterally to heal the wound both from the edges of the blister and also from hair follicles that remain attached to the base of the blister.

We describe the patterns of expression of a range of integrin subunits at different times after blistering, and correlate our findings with the expression of three integrin ligands and three markers of keratinocyte terminal differentiation. We present evidence that the changes in integrin expression that are seen at the time of wound closure are also found in involved psoriatic lesions. Our results raise a number of intriguing questions about integrin function and the factors that regulate integrin expression in hyperproliferative epidermis.

\section{Methods}

Tissue. Sets of five suction blisters, 4-5 $\mathrm{mm}$ in diameter, were induced on hairy thigh or upper arm skin of human volunteers by the application of gentle suction $(600 \mathrm{mmHg})$ for $1-2 \mathrm{~h}$ until a clear, blood-free blister was formed. 6-mm skin punch biopsies were taken under xylocaine local anesthetic at 1, 2, 3, 4, 6, 7, and $14 \mathrm{~d}$, embedded in OCT (Miles Scientific Div., Naperville, IL) and frozen in a liquid nitrogen/ isopentane bath. Tissues from a total of 11 volunteers were examined. The biopsies were taken by I. M. Leigh and colleagues, with prior approval from the Royal London Hospital Ethical Committee. Biopsies of involved psoriatic skin were also obtained by Dr. Irene Leigh, and human neonatal foreskin was used as a control tissue (see reference 7).

Antibodies. The following monoclonal antibodies were generous gifts of the investigators indicated: 5E8 (R. Bankert, Roswell Park Memorial Institute, Buffalo, NY (23)) and P1E5 (E. Wayner, Oncogen Science, Inc. Seattle, WA (11)) against $\alpha_{2} ; \mathrm{J} 143$ against $\alpha_{3}$ (A. Albino, Sloan-Kettering Memorial Institute, New York, NY (24)); MAb 16 

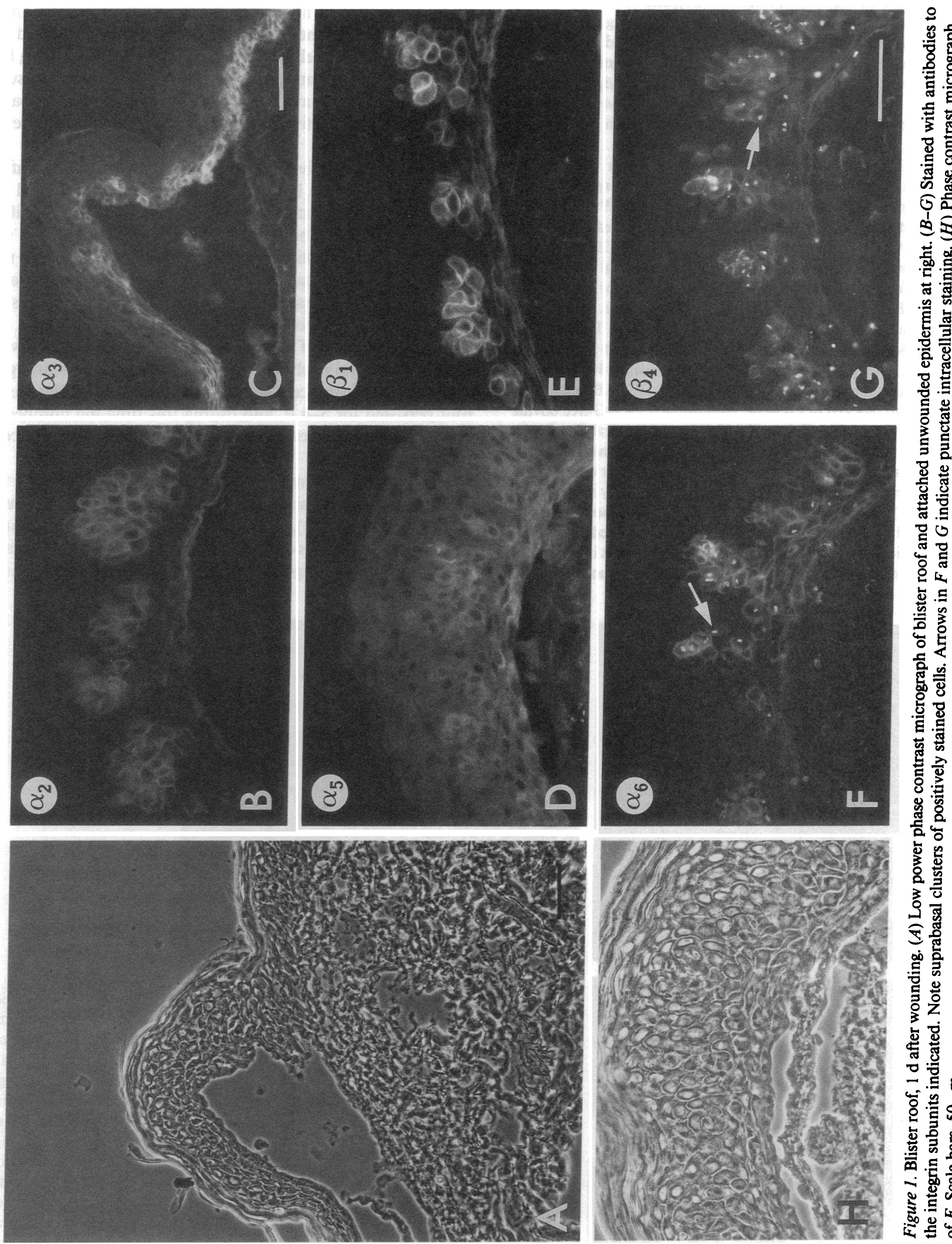

额

总

要

공

oid

范

ㅎํํ

3

迅

0

击

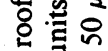

氙

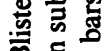

密焉

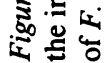


against $\alpha_{5}$ (K. Yamada, NCI, Bethesda, MD (25)); GoH3 against $\alpha_{6}$ (A. Sonnenberg, University of Amsterdam, The Netherlands (26)); 13C2 against $\alpha_{\mathrm{v}}$ (M. Horton, ICRF, London (27)); MAb 13 against $\beta_{1}$ (K. Yamada, NCI, Bethesda, MD (25)); and 3E1 (E. Engvall, La Jolla Cancer Research Foundation, La Jolla, CA (28)) and 439-9B against $\beta_{4}$ (S. Kennel, Oak Ridge National Laboratory, Oak Ridge, TN (29)). P1E6 against $\alpha_{2}$ and VNR147 against $\alpha_{v}$ were purchased from Telios Pharmaceuticals, San Diego, CA. CD29 against $\beta_{1}$ was purchased from Janssen Pharmaceuticals (Geel, Belgium). Y2/51 against $\beta_{3}$ (D. Mason, John Radcliffe Hospital, Oxford (30)) was always negative on foreskin (see also reference 7), and during wound healing and in psoriatic lesions.

Rabbit antihuman fibronectin was purchased from Calbiochem Corp., La Jolla, CA (Novabiochem [UK], Nottingham, England). Rabbit antisera to mouse laminin and human collagen type IV were kindly provided by M. J. Warburton, St. George's Hospital Medical School, London (31). A rabbit antiserum to human involucrin (DH1) was also used (32). Two monospecific antikeratin monoclonal antibodies, LL025 (specific for keratin 16; and LH10 (specific for keratin 10; (Leigh, I. M., P. E. Purkis, P. Whitehead, and E. B. Lane. Manuscript accepted for publication), were kindly provided by $\mathrm{I}$. M. Leigh.

Staining. $6-\mu \mathrm{m}$ frozen sections were cut and stained as described previously (7). Briefly, sections were fixed for $30 \mathrm{~min}$ in $4 \%$ formaldehyde in PBS containing $1 \mathrm{mM} \mathrm{Mg}^{2+}$ and $\mathrm{Ca}^{2+}$ (PBSABC) at room temperature and blocked in PBSABC containing $0.1 \%$ IgG-free bovine serum albumin and $0.02 \%$ Triton X-100 (Sigma Chemical Co., Poole, UK). Primary antibodies were detected with the biotin-streptavidin system (Amersham International, Amersham, UK). For double label immunofluorescence, unfixed sections were sequentially stained with anti- $\alpha_{6}(\mathrm{GoH} 3)$, FITC-conjugated sheep anti-rat IgG (Amersham International), rabbit anti-involucrin (DH1), and Texas Red-conjugated goat anti-rabbit IgG (Amersham International). Controls in which primary antibodies were omitted showed no nonspecific fluorescence.

\section{Results}

Normal epidermis. Sections of human foreskin were stained at the same time as the suction blister specimens and acted as positive controls. In normal epidermis integrin expression is largely confined to the basal layer: $\beta_{1}$, its $\alpha$ partners, and $\alpha_{v}$ have a uniform pericellular distribution, although staining for $\alpha_{v}$ and $\alpha_{5}$ is weaker and more diffuse than for the other subunits. $\alpha_{6}$ and $\beta_{4}$ also have a pericellular distribution in the basal layer, but show a relative concentration at the basement membrane zone (7).

$1 d$ after blister formation. The staining pattern $1 \mathrm{~d}$ after blistering is shown in Fig. 1. The epidermis that remained attached to the dermis at the blister edges had the same distribution of integrins as in normal, undamaged epidermis (Fig. 1 C). Integrin-positive keratinocytes within the blister roof were not organized as a single basal layer (Fig. 1), but instead, suprabasal clusters of cells expressing integrins were observed. This distribution was observed for all integrin subunits tested $\left(\alpha_{2}, \alpha_{3}, \alpha_{5}\right.$, $\left.\beta_{1}, \alpha_{v}, \alpha_{6}, \beta_{4}\right)$. Most of the cells within the blister roof that were expressing $\alpha_{6}$ and $\beta_{4}$ showed punctate intracellular staining in addition to cell surface staining (Fig. $1, F$ and $G$ ). The blister roof persisted for 3-4 d, and during this time the number of positive clusters decreased, and more individual positive cells were observed.

$2 d$. By 2 d, lateral migration of keratinocytes from the edges of the wound and from hair follicles within the wound was underway $(20,33)$, although a tongue of migrating keratinocytes was not always clearly visible (e.g., Fig. $2 \mathrm{~A}$ ). The staining pattern of the migrating keratinocytes was the same as in
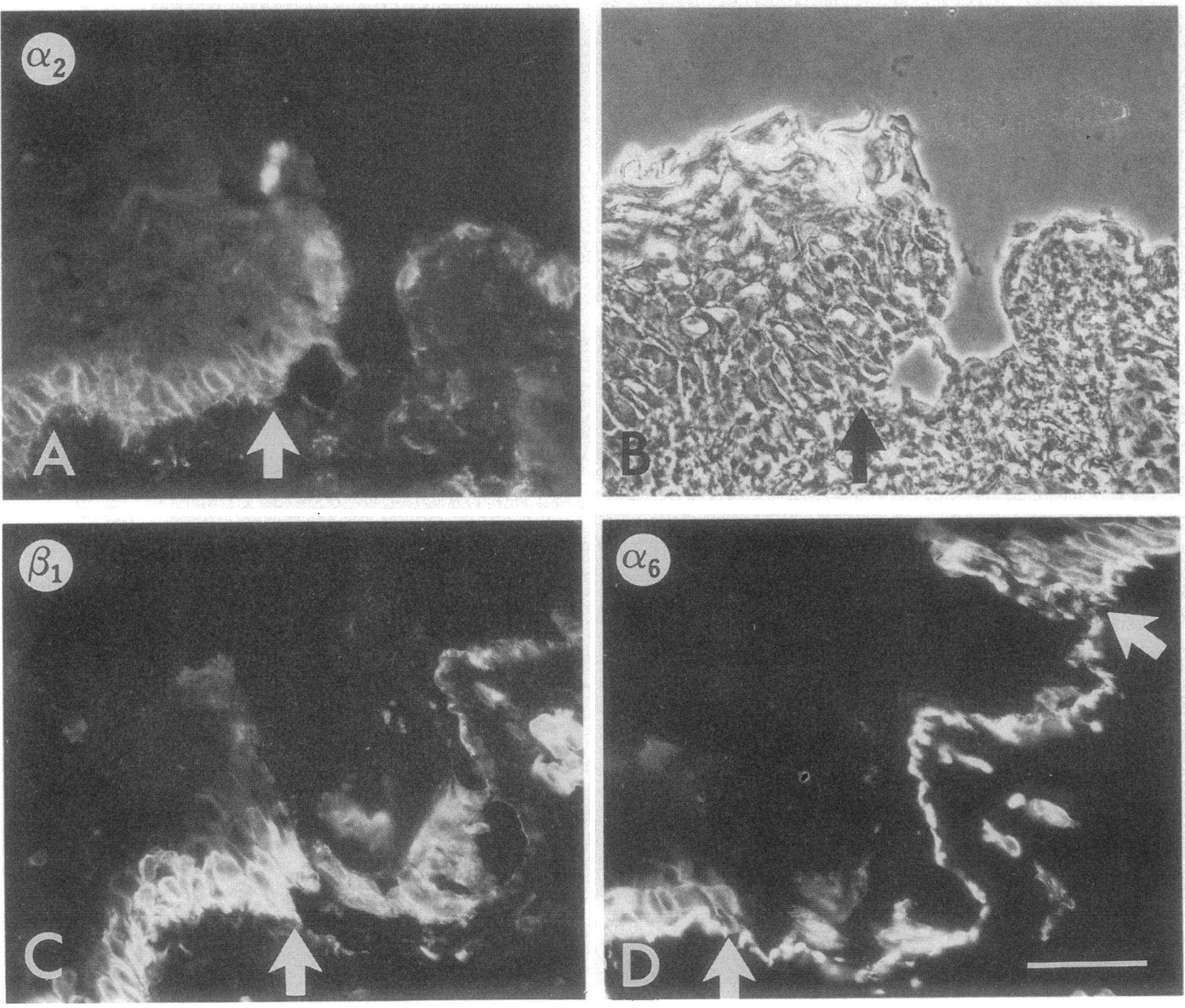

Figure 2. $2 \mathrm{~d}$ after wounding. $(A, C, D)$ Stained with antibodies to the integrin subunits indicated. (B) Phase contrast micrograph of $A$. Keratinocytes are migrating towards the right in $A, B$, and $C$. In $D$ keratinocytes are migrating towards the center from both sides of the field. Arrows indicate the leading edges. There appears to be staining of membrane fragments on the exposed basement membrane. Scale bar, $50 \mu \mathrm{m}$. 
normal undamaged epidermis: all subunits were confined to the basal layer, and the cellular distribution of each integrin was normal (Fig. 2). Some staining of the denuded basement membrane was also detected (for example, Fig. 2, $C$ and $D$ ), possibly reflecting staining of basal cell membrane fragments that had been left behind (21). No changes in integrin expression were observed distal to the migrating wound edge (not shown).

$3 d$. By 3 d, faint suprabasal staining for $\alpha_{3}$ (Fig. $3 C$ ) and $\beta_{1}$ (not shown) was seen at the leading edge of the migrating epidermis. Within $1 \mathrm{~mm}$ from the leading edge, $\alpha_{3}$ and $\beta_{1}$ were confined to the basal layer. The staining patterns of all the other integrin subunits were unchanged at $3 \mathrm{~d}$ (see for example, Fig. $3 A$ ).

$4 d$. By $4 \mathrm{~d}$, wound closure had occurred in most specimens examined. $\alpha_{6}$, in addition to $\alpha_{3}$ and $\beta_{1}$, was expressed in suprabasal cells at the center of the wound (not shown). As before, the staining pattern distal to the wounds was normal and all the other integrin subunits, including $\beta_{4}$, were confined to the basal layer at the site of the wound.

6-7 d. 6-7 d after blistering, all of the wounds had reepithelialized, but the epidermis was hyperproliferative: it was thicker than normal epidermis and the basal cells were vertically elongated (Fig. $4 C$ ). $\alpha_{2}, \alpha_{3}, \alpha_{6}$, and $\beta_{1}$ were found in all the living cell layers at the center of the wound (Fig. 4). The strong pericellular staining suggested that the integrins were present at the cell surface and not accumulated intracellularly. Suprabasal expression extended almost to the edge of the biopsies, declining gradually to basally restricted staining (Fig. $4 H$ ). Suprabasal $\alpha_{v}$ was weak or absent on all but one specimen, in which the suprabasal cell layers were highly disorganized and staining was strong, compared with normal epidermis (Fig. $4 I$ ). $\alpha_{5}$ remained confined to the basal layer (Fig. $4 \mathrm{~A}$ ), and $\beta_{4}$ stained the basal and sometimes the first suprabasal layers (Fig. $4 G$ ).

$2 w k$. 2 wk after wounding, the epidermis was morphologically normal (Fig. 5), and expression of all integrin subunits was once more largely confined to the basal layer (Fig. 5 and results not shown). The intensity of staining was somewhat greater than in normal skin.

Terminal differentiation markers. The suprabasal integrin staining observed 1 wk after blistering suggested that keratinocytes were expressing integrins while undergoing terminal differentiation. Three markers of terminal differentiation were therefore examined: keratin 10 , which is expressed by all supra-
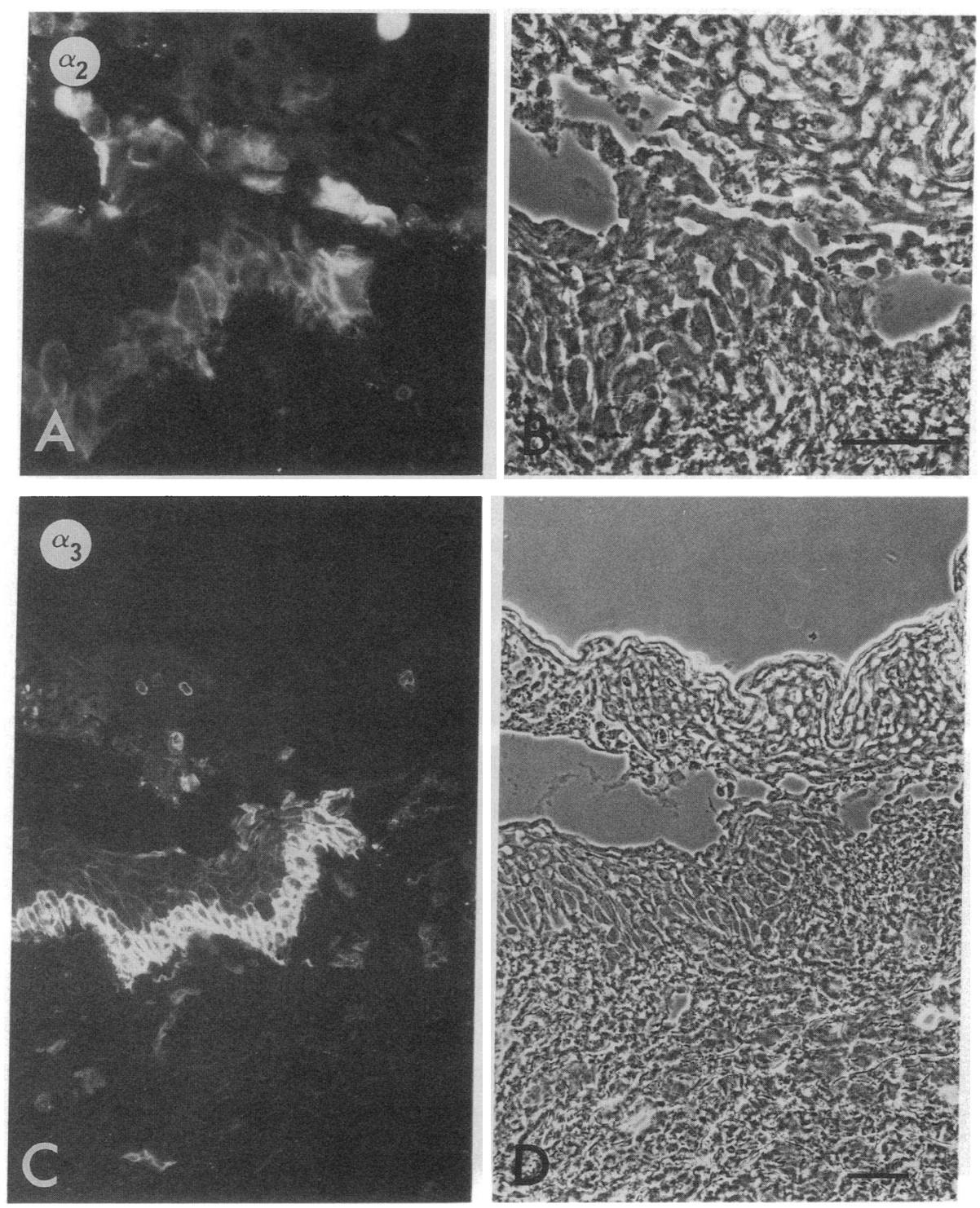

Figure $3.3 \mathrm{~d}$ after wounding. $(A, C)$ Stained with antibodies to the integrin subunits indicated. $(B, D)$ Phase contrast micrographs of $A, C$, respectively. Keratinocytes are migrating towards the right. Note that there is suprabasal staining in $C$, but not in $A$. Scale bar, $50 \mu \mathrm{m}$. 

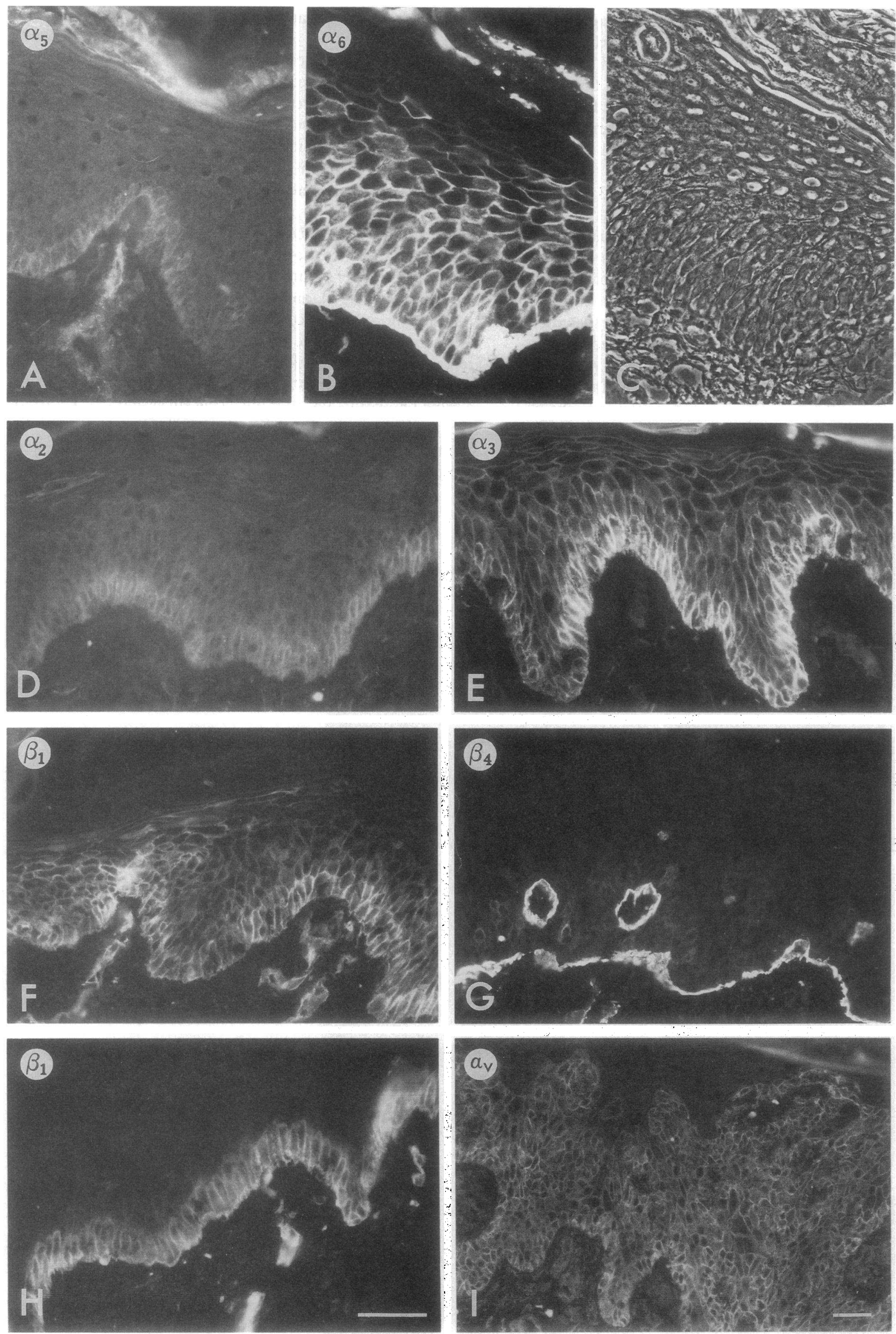

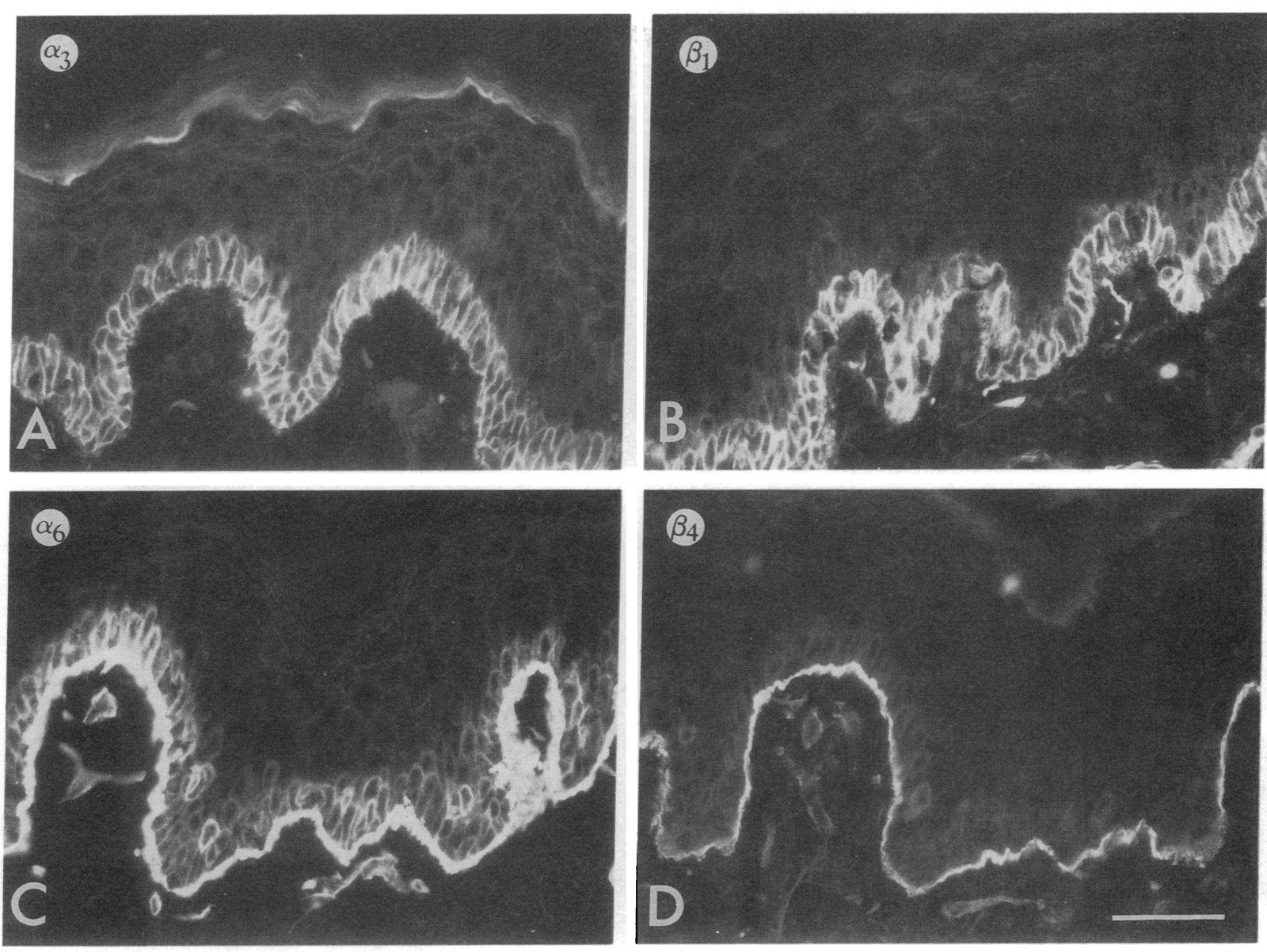

Figure 5. $2 \mathrm{wk}$ after wounding. $(A-D)$ Stained with antibodies to the integrin subunits indicated. Scale bar, $50 \mu \mathrm{m}$.

basal cells in normal epidermis $(34,35)$; keratin 16 , which is expressed suprabasally in hyperproliferative epidermis $(36$, 37 ); and involucrin, a precursor of the cornified envelope. Involucrin is normally first expressed in the upper spinous layers of the epidermis, but expression begins in the lower spinous layers under hyperproliferative conditions (Fig. 6, $B$ and $D$ ) $(38,39)$.

Keratins 10 and 16 were expressed in the suprabasal cell layers 1 wk after wounding (Fig. 6, $E$ and $F$ ). Involucrin expression began in the lower spinous layers, and double label immunofluorescence showed coexpression of involucrin with $\alpha_{6}$ (Fig. 6, $C$ and $D$ ) and $\beta_{1}$ integrin subunits (not shown) suprabasally. Distal to the center of the wound, involucrin expression began higher in the spinous layers, and the integrins were confined to the basal layer: the involucrin-positive cells were integrin-negative (Fig. 6, $A$ and $B$ ).

Extracellular matrix proteins. Biopsies taken 1 wk after wounding were stained with antibodies to fibronectin, type IV collagen and laminin, to see whether these integrin ligands were, like their receptors, present in the suprabasal layers. All three proteins were present in the dermis and basement membrane zone (Fig. 6, $G$ and $H$ and results not shown), in the same distribution as in unwounded epidermis (7). They were absent from the suprabasal layers, apart from some areas where the keratinocyte layers were disorganized and faint, diffuse staining was observed (Fig. $6 \mathrm{H}$ ).

Psoriasis. The morphological appearance of the epidermis 1 wk after wounding, together with $\mathrm{K} 16$ expression and premature involucrin expression, indicated that the tissue was hyperproliferative. To discover whether suprabasal integrin expression is peculiar to wound healing or may be a more general feature of hyperproliferative epidermis, we stained sections of involved psoriatic lesions. There was suprabasal staining for two of the three subunits examined, $\alpha_{6}$ and $\beta_{1}$, while $\beta_{4}$ remained basally restricted (Fig. 7). In contrast to wounded epidermis, however, the suprabasal staining in psoriatic epidermis was confined to discrete patches of cells (Fig. 7). Expression of involucrin was found in the lower spinous layers, coexpressed with $\alpha_{6}$ and $\beta_{1}$ (not shown), as found at 6-7 d in the wound.

\section{Discussion}

The morphological changes associated with the reepithelialization of suction blister wounds to human skin have been well documented $(20,21)$. We have analyzed integrin expression during the healing process and have found a number of changes in the localization of integrin subunits, compared with

Figure $4.7 \mathrm{~d}$ after wounding. $(A, B, D-I)$ Stained with antibodies to the integrin subunits indicated. $(C)$ Phase contrast micrograph of $B$. $(H)$ Edge of wound. (I) Note disorganized cell layers. Scale bars in $H$ and $I, 50 \mu \mathrm{m}$. $A-H$ are at the same magnification. 

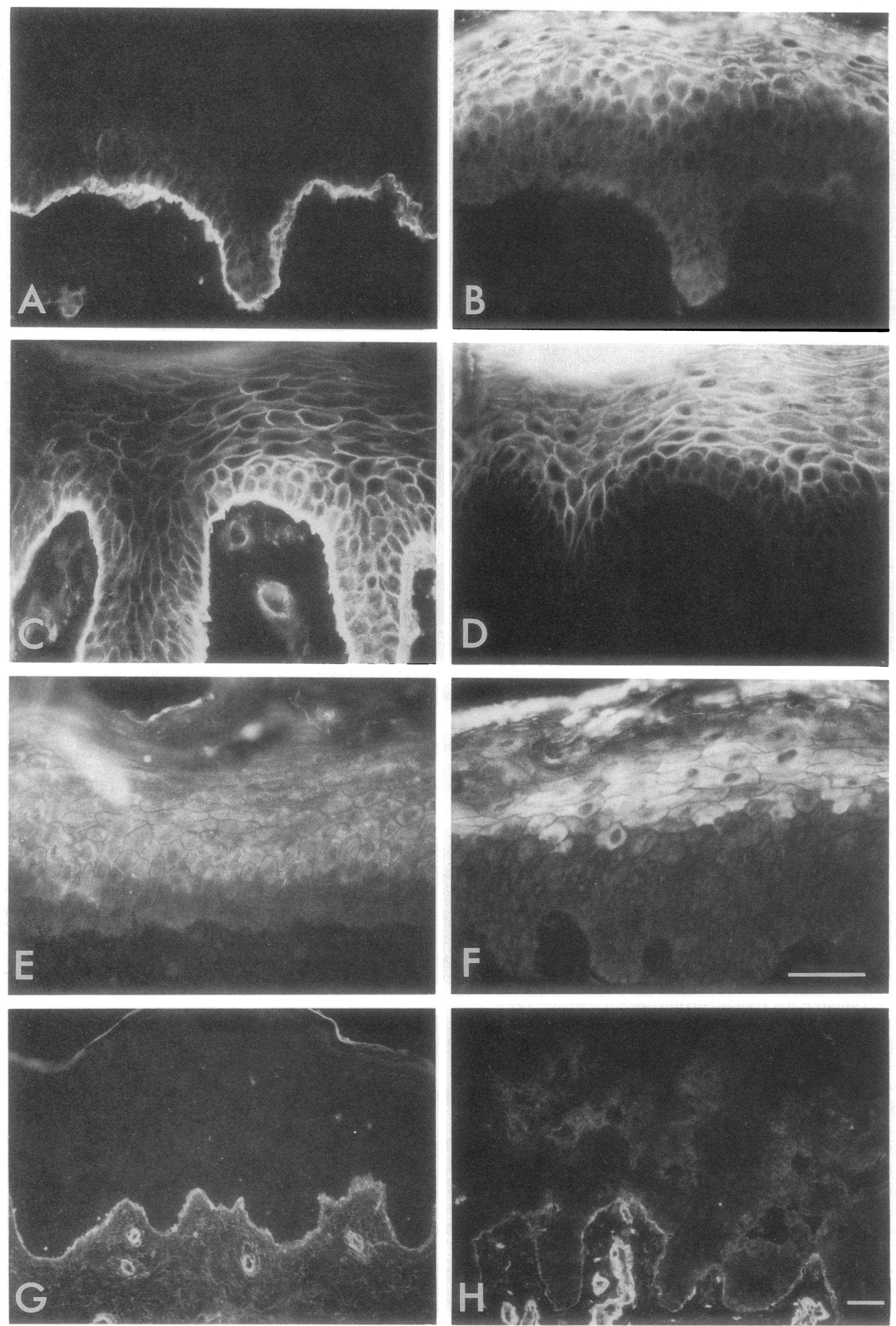
normal unwounded epidermis. The most significant observation was strong suprabasal expression of several integrins at $7 \mathrm{~d}$ after wound closure, in contrast to the pattern seen in normal unwounded epidermis.

The blister roof. Integrins can be detected in the blister roof up until it detaches at about $3 \mathrm{~d}$ after wounding. Whereas in normal attached epidermis integrins are largely confined to the basal layer, clusters of integrin-positive suprabasal cells were found in the blister roof at $24 \mathrm{~h}$. At later times, individual positively stained cells and clusters were scattered throughout the blister roof. Intracellular punctate staining with antibodies to $\alpha_{6}$ and $\beta_{4}$ was observed, and this probably reflects internalization of hemidesmosomes and associated $\alpha_{6} \beta_{4}(13,14)$ during detachment of the epidermis $(40,41)$. Our observations are consistent with the proposal that basal cells are pulled upwards into a suprabasal position by the mechanical forces used to create the blister. Basal and suprabasal cells differ in their cohesiveness, and this may explain why basal cells were initially found as clusters (42).

Lateral migration of keratinocytes. In normal epidermis keratinocyte migration is restricted to movement upwards from the basal layer, but during wound healing keratinocytes also migrate laterally. This change in behavior has been termed "activation"; it is proposed to occur not only on wounding, but also when keratinocytes are placed in culture, and it is correlated with changes in adhesiveness (reviewed in references 18 , 43). Thus, when keratinocytes are first isolated from skin, they adhere poorly to fibronectin, but with time in culture they develop adhesiveness to fibronectin $(44,45)$ and also show increased migration on type I collagen and fibronectin (46). In contrast to normal keratinocytes, cells taken directly from a wound bed are capable of adhering to fibronectin immediately (47). In wounds in which the basement membrane is destroyed, fibronectin forms the provisional matrix over which keratinocytes migrate (reviewed in reference 48) and accumulates in wound fluid, including the fluid of suction blisters (49). Guo et al. (50) have reported increased expression of the $\alpha_{5} \beta_{1}$ fibronectin receptor by keratinocytes migrating out of skin explants.

In view of such findings, we were surprised to observe that during the initial stages of keratinocyte migration in suction blister wounds (until $3 \mathrm{~d}$ ) there were no changes in integrin expression, compared with normal epidermis: the same subunits were present, with the same relative staining intensity and the same cellular distribution. One possible explanation for the lack of changes is that since in suction blisters the basement membrane remains intact, the composition of the extracellular matrix over which the cells migrate may be relatively unchanged. Furthermore, it is well established that integrin function can be up- or downregulated in the absence of changes in expression (see for example, references 12, 51), and so the lack of changes in staining pattern cannot be taken as evidence for unaltered integrin function. In corneal wounds, the presence or absence of a basement membrane does not significantly affect staining patterns of $\alpha_{5}$ and $\alpha_{6}(52)$.

Hemidesmosomes assemble at the basal surface of basal keratinocytes during the lateral migration phase of wound healing, but there is some disagreement as to how far from the migrating edge they first form. There is evidence from electron
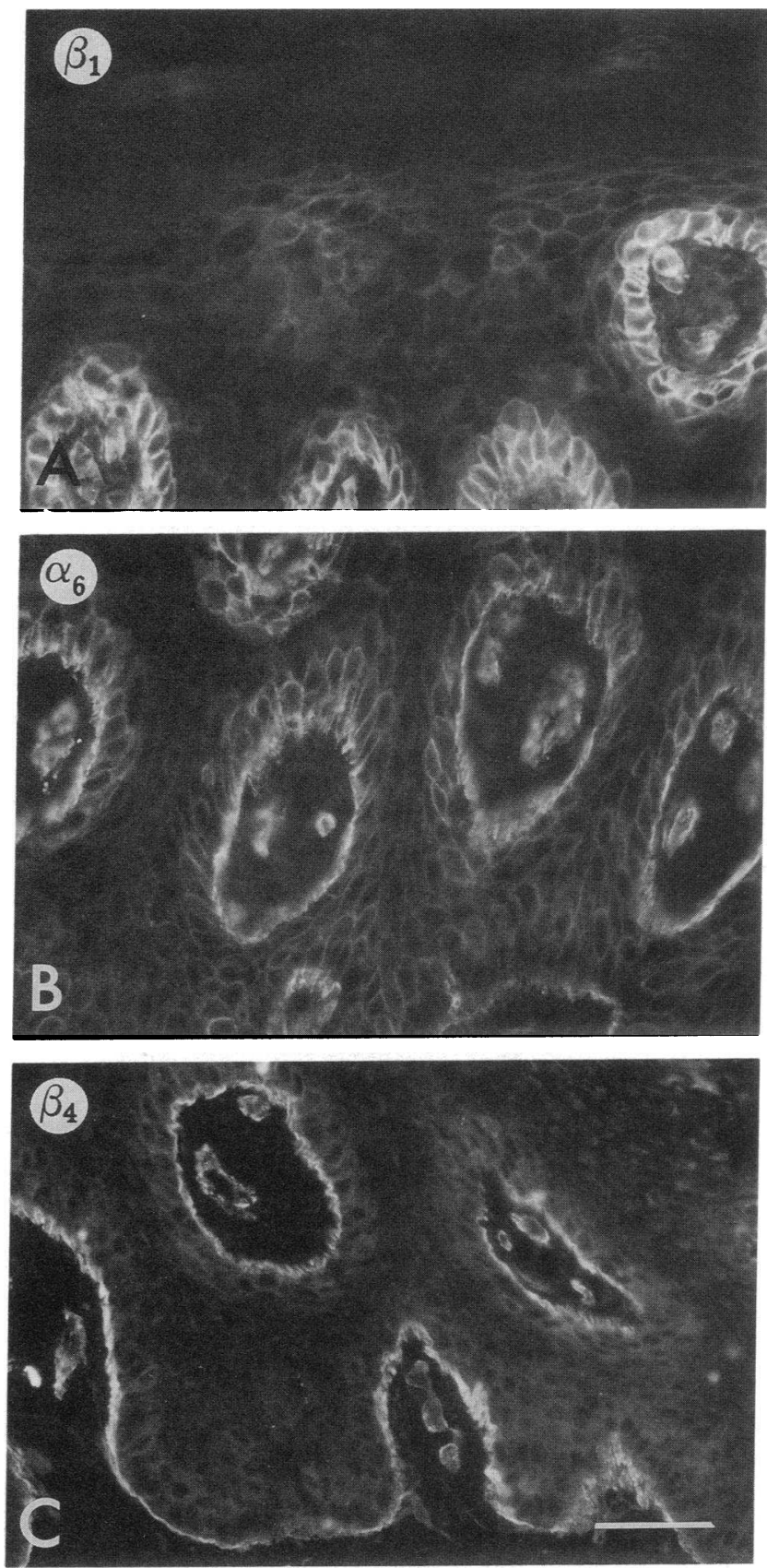

Figure 7. Involved psoriatic lesion stained with antibodies to the integrin subunits indicated. Note patches of suprabasal staining in $A$ and $B$. Scale bar, $50 \mu \mathrm{m}$.

microscopy (53) and staining for bullous pemphigoid antigen (a component of hemidesmosomes; 54, 55) that hemidesmosomes are formed in the leading cell. However, others have reported that they first appear several cells behind the leading cell $(17,43) . \alpha_{6} \beta_{4}$ is not restricted to hemidesmosomes $(14)$, but at the time of hemidesmosome assembly during epidermal development there is a redistribution of $\alpha_{6} \beta_{4}$ so that it becomes concentrated at the basement membrane zone (7). Kurpakus et

Figure 6. Terminal differentiation markers and extracellular matrix proteins, $1 \mathrm{wk}$ after wounding. $(A-D)$ Dual labeling for $\alpha_{6}(A, C)$ and involucrin $(B, D) .(A, B)$ Distal to wound center; $(C-H)$ center of wound. $(E)$ Keratin $10 ;(F)$ keratin 16. $(G)$ Fibronectin; $(H)$ laminin. Scale bars, $50 \mu \mathrm{m} ; A-F$ are at same magnification, $G$ and $H$ both at lower magnification. 
al. (56) have also reported a correlation between polarized $\alpha_{6} \beta_{4}$ expression and hemidesmosome assembly in migrating corneal epithelial cells. We observed a concentration of $\alpha_{6} \beta_{4}$ at the basement membrane zone right up to the migrating edge in the wounds (Fig. $2 \mathrm{D}$ ). Although this might tend to support the conclusion that hemidesmosomes are assembled in the leading cell, further experiments will be required to resolve the issue.

Suprabasal integrin expression. The most striking difference between normal and healing epidermis we observed was at the time of wound closure, when several of the integrin subunits were found on the surface of suprabasal keratinocytes. Our results are broadly in agreement with those of others, who have also observed suprabasal integrin staining during healing of deep skin wounds $(48,57)$ and in corneal abrasions and keratectomies (52). The first subunits to show a suprabasal location were $\alpha_{3}$ and $\beta_{1}$ (from $3 \mathrm{~d}$ ), followed by $\alpha_{6}(4 \mathrm{~d})$, then $\alpha_{2}$. $\alpha_{5}$ and $\beta_{4}$ remained primarily confined to the basal layer, and $\alpha_{\mathrm{v}}$ was only found suprabasally in one specimen, in which the keratinocytes were disorganized. It is interesting that $\alpha_{3} \beta_{1}$ was the first integrin to be detected suprabasally, since it is also one of the earliest integrins to be expressed during epidermal development (7). The observation that $\alpha_{6}$ was expressed in all living suprabasal layers, whereas its normal partner in keratinocytes, $\beta_{4}(6,8,58,59)$, was not, suggests that $\alpha_{6}$ may form a heterodimer with $\beta_{1}$ in the suprabasal layers, since monomeric integrins are not found on the cell surface $(60,61)$.

An important question that remains to be answered is whether or not the suprabasal integrins are functional. We could not detect significant levels of three of the integrin ligands, fibronectin, type IV collagen, and laminin, suprabasally, but the integrins might nevertheless be functional in cellcell adhesion $(11,15)$. During terminal differentiation in culture keratinocytes show a reduced adhesiveness to extracellular matrix proteins before overt terminal differentiation; in the case of $\alpha_{5} \beta_{1}$, downregulation of ligand binding ability without a reduction in the amount of receptor on the cell surface has been demonstrated on commitment to terminal differentiation (12). Since the suprabasal integrin-positive cells were expressing three markers of terminal differentiation, keratins 10 and 16 and involucrin, it is possible that the integrins, though expressed, are functionally downregulated in the suprabasal layers.

In culture, integrin gene transcription is switched off when keratinocytes undergo terminal differentiation and the half life of the $\beta_{1}$ integrins under those conditions is about $12-16 \mathrm{~h}$ (Hotchin, N. A., and F. M. Watt. Manuscript submitted for publication; (12)). Assuming that the half life of the subunits is similar in vivo, it is considerably shorter than the transit time from the basal layer to the tissue surface, even in hyperproliferative epidermis $(4-8 \mathrm{~d}$ in psoriasis $(62,63))$. Thus, either the half life of the proteins is longer in vivo, or the suprabasal terminally differentiating keratinocytes are synthesizing integrin subunits de novo.

By the criteria of morphology, keratin 16 expression and premature involucrin expression, the epidermis is hyperproliferative at $7 \mathrm{~d}(36,38,64)$ when the integrins are suprabasal, and has returned to normal by $14 \mathrm{~d}$ when the integrins are once more confined to the basal layer. In psoriasis, a benign hyperproliferative disorder, we noted patches of suprabasal integrin expression, as also reported by Ralfkiaer et al. (65). However, it seems unlikely that suprabasal integrin expression is a marker of hyperproliferation per se, since keratinocytes in culture are also hyperproliferative by these criteria (39), and yet in strati- fied cultures very little suprabasal integrin staining is observed $(8,66)$. An alternative explanation is that suprabasal integrin expression is a response of keratinocytes to the inflammation characteristic of wounds and psoriatic lesions (reviewed in (67, 68)) through which keratinocytes are exposed to a wide range of cytokines (reviewed in reference 19). Integrin expression in other cell types is known to be upregulated by a number of cytokines and growth factors that are present in wounds (reviewed in reference 69), and it will be interesting to test their effects on keratinocytes.

Studies with cultured keratinocytes suggest a role for integrins in regulating cell-ECM adhesion, cell-cell adhesion, and the initiation of terminal differentiation $(6,11,12,15)$. During development, there are marked changes in the types of integrin subunits expressed and their location within the epidermal basal layer (7). We have now demonstrated that during wound healing and in psoriasis, integrin expression is not downregulated at the onset of terminal differentiation. Taken together, these results suggest that integrin expression is subject to complex regulatory mechanisms, probably both environmental and developmentally programed. The functional consequences of this dynamic regulation remain to be investigated.

\section{Acknowledgments}

We are grateful to all the investigators who generously gave us antibodies; to the volunteers who donated tissue; and to the ICRF Histopathology Unit for technical assistance.

\section{References}

1. Hynes, R. O. 1987. Integrins: a family of cell surface receptors. Cell. 48:549-554.

2. Hemler, M. E. 1990. VLA proteins in the integrin family: structures, functions and their role on leukocytes. Annu. Rev. Immunol. 8:365-400.

3. Ruoslahti, E. 1991. Integrins. J. Clin. Invest. 87:1-5.

4. Wayner, E. A., W. G. Carter, R. S. Piotrowicz, and T. J. Kunicki. 1988. The function of multiple extracellular matrix receptors in mediating cell adhesion to extracellular matrix: preparation of monoclonal antibodies to the fibronectin receptor that specifically inhibit cell adhesion to fibronectin and react with platelet glycoproteins Ic-IIa. J. Cell Biol. 107:1881-1891.

5. Peltonen, J., H. Larjava, S. Jaakkola, H. Gralnick, S. K. Akiyama, S. S. Yamada, K. M. Yamada, and J. Uitto. 1989. Localization of integrin receptors for fibronectin, collagen, and laminin in human skin. J. Clin. Invest. 84:19161923.

6. De Luca, M., R. N. Tamura, S. Kajiji, S. Bondanza, P. Rossino, R. Cancedda, P. C. Marchisio, and V. Quaranta. 1990. Polarized integrin mediates human keratinocyte adhesion to basal lamina. Proc. Natl. Acad. Sci. USA. 87:68886892.

7. Hertle, M. D., J. C. Adams, and F. M. Watt. 1991. Integrin expression during human epidermal development in vivo and in vitro. Development (Camb.) 112:193-206.

8. Adams, J. C., and F. M. Watt. 1991. Expression of $\beta_{1}, \beta_{3}, \beta_{4}$, and $\beta_{5}$ integrins by human epidermal keratinocytes and nondifferentiating keratinocytes. J. Cell Biol. 115:829-841.

9. Marchisio, P. C., S. Bondanza, O. Cremona, R. Cancedda, and M. De Luca. 1991. Polarized expression of integrin receptors $\left(\alpha_{6} \beta_{4}, \alpha_{2} \beta_{1}, \alpha_{3} \beta_{1}\right.$, and $\left.\alpha_{v} \beta_{5}\right)$ and their relationship with the cytoskeleton and basement membrane matrix in cultured human keratinocytes. J. Cell Biol. 112:761-773.

10. Staquet, M. J., B. Levarlet, C. Dezutter-Dambuyant, D. Schmitt, and J. Thivolet. 1990. Identification of specific human epithelial cell integrin receptors as VLA proteins. Exp. Cell Res. 187:277-283.

11. Carter, W. G., E. A. Wayner, T. S. Bouchard, and P. Kaur. 1990. The role of integrins $\alpha_{2} \beta_{1}$ and $\alpha_{3} \beta_{1}$ in cell-cell and cell-substrate adhesion of human epidermal cells. J. Cell Biol. 110:1387-1404.

12. Adams, J. C., and F. M. Watt. 1990. Changes in keratinocyte adhesion during terminal differentiation: reduction in fibronectin binding precedes $\alpha_{5} \beta_{1}$ integrin loss from the cell surface. Cell. 63:425-435.

13. Stepp, M. A., S. Spurr-Michaud, A. Tisdale, J. Elwell, and I. K. Gipson. 1990. $\alpha_{6} \beta_{4}$ integrin heterodimer is a component of hemidesmosomes. Proc. Natl. Acad. Sci. USA. 87:8970-8974.

14. Sonnenberg, A., J. Calafat, H. Janssen, H. Daams, L. M. H. van der 
Raaij-Helmer, R. Falcioni, S. J. Kennel, J. D. Aplin, J. Baker, M. Loizidou, and D. Garrod. 1991. Integrin $\alpha_{6} / \beta_{4}$ complex is located in hemidesmosomes, suggesting a major role in epidermal cell-basement membrane adhesion. J. Cell Biol. 113:907-917.

15. Larjava, H., J. Peltonen, S. K. Akiyama, S. S. Yamada, H. R. Gralnick, J. Uitto, and K. M. Yamada. 1990. Novel function for $\beta_{1}$ integrins in keratinocyte cell-cell interactions. J. Cell Biol. 110:803-815.

16. Adams, J. C., and F. M. Watt. 1989. Fibronectin inhibits the terminal differentiation of human keratinocytes. Nature (Lond.) 340:307-309.

17. Odland, G., and R. Ross. 1968 . Human wound repair. I. Epidermal regeneration. J. Cell Biol. 39:135-151.

18. Grinnell, F. 1990. The activated keratinocyte: up regulation of cell adhesion and migration during wound healing. J. Trauma. 30:S144-149.

19. McKay, I. A., and I. M. Leigh. 1991. Epidermal cytokines and their roles in cutaneous wound healing. Br. J. Dermatol. 124:513-518.

20. Kiistala, U., and K. K. Mustakallio. 1967. Dermo-epidermal separation with suction. Electron microscopic and histochemical study of initial events of blistering on human skin. J. Invest. Dermatol. 48:466-477.

21. Hunter, J. A. A., E. McVittie, and J. S. Comaish. 1974. Light and electron microscopic studies of physical injury to the skin. I. Suction. Br. J. Dermatol. 90:481-490.

22. Lowe, L. B., and J. C. van der Leun. 1968. Suction blisters and dermo-epidermal adherence. J. Invest. Dermatol. 50:308-314.

23. Zylstra, S., F. A. Chen, S. K. Ghosh, E. A. Repasky, U. Rao, H. Takita, and R. B. Bankert. 1986. Membrane-associated glycoprotein (gp 160) identified on human lung tumors by a monoclonal antibody. Cancer Res. 46:6446-6451.

24. Kantor, R. R. S., M. J. Mattes, K. O. Lloyd, L. J. Old, and A. P. Albino 1987. Biochemical analysis of two cell surface glycoprotein complexes, very common antigen 1 and very common antigen 2. J. Biol. Chem. 262:15158-15165.

25. Akiyama, S. K., S. S. Yamada, W.-T. Chen, and K. M. Yamada. 1989. Analysis of fibronectin receptor function with monoclonal antibodies: roles in cell adhesion, migration, matrix assembly, and cytoskeletal organization. J. Cell Biol. 109:863-875.

26. Sonnenberg, A., H. Daams, M. A. van der Valk, J. Hilken, and J. Hilgers 1986. Development of mouse mammary gland: identification of stages in differentiation of luminal and myoepithelial cells using monoclonal antibodies and polyvalent antiserum against keratin. $J$. Histochem. Cytochem. 34:1037-1046.

27. Horton, M. A., D. Lewis, K. McNulty, J. A. S. Pringle, and T. J. Chambers. 1985. Monoclonal antibodies to osteoclastomas (giant cell bone tumors): definition of osteoclast-specific cellular antigens. Cancer Res. 45:56635669.

28. Ryynanen, J., S. Jaakkola, E. Engvall, J. Peltonen, and J. Uitto. 1991. Expression of $\beta_{4}$ integrins in human skin: comparison of epidermal distribution with $\beta_{1}$-integrin epitopes, and modulation by calcium and vitamin $D_{3}$ in cultured keratinocytes. J. Invest. Dermatol. 97:562-567.

29. Kennel, S. J., L. J. Foote, R. Falcioni, A. Sonnenberg, C. D. Stringer, C. Crouse, and M. E. Hemler. 1989. Analysis of the tumor-associated antigen TSP180. J. Biol. Chem. 264:15515-15521.

30. von dem Borne, A. E. G. K., P. W. Modderman, L. G. Admiraal, and J. K Nieuwenhuis. 1989. In Leucocyte Typing IV. W. Knapp, editor. Oxford University Press, Oxford. p. 951.

31. Warburton, M. J., S. A. Ferns, and P. S. Rudland. 1982. Enhanced synthesis of basement membrane proteins during the differentiation of rat mammary tumor epithelial cells into myoepithelial-like cells in vitro. Exp. Cell Res. 137:373-380.

32. Dover, R., and F. M. Watt. 1987. Measurement of the rate of epidermal terminal differentiation: expression of involucrin by S-phase keratinocytes in culture and in psoriatic plaques. J. Invest. Dermatol. 89:349-352.

33. Ortonne, J.-P., T. Loning, D. Schmitt, and J. Thivolet. 1981. Immunomorphological and ultrastructural aspects of keratinocyte migration in epidermal wound healing. Virchows Arch. 392:217-230.

34. Fuchs, E., and H. Green. 1980. Changes in keratin gene expression during terminal differentiation of the keratinocyte. Cell. 19:1033-1042.

35. Galvin, S., C. Loomis, M. Manabe, D. Dhouailly, and T.-T. Sun. 1989. The major pathways of keratinocyte differentiation as defined by keratin expression: an overview. Adv. Dermatol. 4:277-300.

36. Weiss, R. A., R. Eichner, and T.-T. Sun. 1984. Monoclonal antibody analysis of keratin expression in epidermal diseases: a 48- and 56-kdalton keratin as molecular markers for hyperproliferative keratinocytes. J. Cell Biol. 98:13971406.

37. Stoler, A., R. Kopan, M. Duvic, and E. Fuchs. 1988. Use of monospecific antisera and cRNA probes to localize the major changes in keratin expression during normal and abnormal epidermal differentiation. J. Cell Biol. 107:427446.

38. Bernard, B. A., A. Reano, Y. M. Darmon, and J. Thivolet. 1986. Precocious appearance of involucrin and epidermal transglutaminase during differentiation of psoriatic skin. Br. J. Dermatol. 114:279-283.

39. Watt, F. M., P. Boukamp, J. Hornung, and N. E. Fusenig 1987. Effect of growth environment on spatial expression of involucrin by human epidermal keratinocytes. Arch. Dermatol. Res. 279:335-340.
40. Takahashi, Y., D. F. Mutasim, H. P. Patel, G. J. Anhalt, R. S. Labib, and L. A. Diaz. 1985. The use of human pemphigoid autoantibodies to study the fate of epidermal basal cell hemidesmosomes after trypsin dissociation. J. Invest. Dermatol. 85:309-313.

41. Willsteed, E. M., B. S. Bhogal, A. Das, S. S. Bekir, F. Wojnarowska, M. M. Black, and P. H. McKee. 1991. An ultrastructural comparison of dermo-epidermal separation techniques. J. Cutaneous Pathol. 18:8-12.

42. Watt, F. M. 1984. Selective migration of terminally differentiating cells from the basal layer of cultured human epidermis. J. Cell Biol. 98:16-21.

43. Grinnell, F. 1992. Wound repair, keratinocyte activation, and integrin modulation. J. Cell Sci. 101:1-5.

44. Takashima, A., and F. Grinnell. 1985. Fibronectin-mediated keratinocyte migration and initiation of fibronectin receptor function in vitro. J. Invest. Dermatol. 85:304-308.

45. Grinnell, F., K.-I. Toda, and A. Takashima. 1987. Activation of keratinocyte fibronectin receptor function during cutaneous wound healing. J. Cell Sci. Suppl. 8:199-209.

46. Guo, M., K.-I. Toda, and F. Grinnell. 1990. Activation of human keratinocyte migration on type I collagen and fibronectin. J. Cell Sci. 96:197-205.

47. Takashima, A., R. E. Billingham, and F. Grinnell. 1986. Activation of rabbit keratinocyte fibronectin receptor function in vivo during wound healing. $J$. Invest. Dermatol. 86:585-590.

48. Clark, R. A. F. 1990. Fibronectin matrix deposition and fibronectin receptor expression in healing and normal skin. J. Invest. Dermatol. 96:128S-134S.

49. Wysocki, A. B., and F. Grinnell. 1990. Fibronectin profiles in normal and chronic wound fluid. Lab. Invest. 63:825-831.

50. Guo, M., L. T. Kim, S. K. Akiyama, H. R. Gralnick, K. M. Yamada, and F. Grinnell. 1991. Altered processing of integrin receptors during keratinocyte activation. Exp. Cell Res. 195:315-322.

51. Du, X., E. F. Plow, A. L. Frelinger, T. E. O’Toole, J. C. Loftus, and M. H Ginsberg. 1991. Ligands "activate" integrin $\alpha_{\mathrm{mb}} \beta_{3}$ (platelet GPIIb-IIIa). Cell. 65:409-416.

52. Grushkin-Lerner, L. S., and V. Trinkaus-Randall. 1991. Localization of integrin and syndecan in vivo in a corneal epithelial abrasion and keratectomy. Curr. Eye Res. 10:75-85.

53. Krawczyk, W. S. 1971. A pattern of epidermal cell migration during wound healing. J. Cell Biol. 49:247-263.

54. Robledo, M. A., S. C. Kim, N. J. Korman, J. R. Stanley, R. S. Labib, S. Futamura, and G. J. Anhalt. 1990. Studies of the relationship of the 230-kD and 180-kD bullous pemphigoid antigens. J. Invest. Dermatol. 94:793-797.

55. Stanley, J. R., O. M. Alvarez, E. W. J. Bere, W. M. Eaglstein, and S. I. Katz. 1981. Detection of basement membrane zone antigens during epidermal wound healing in pigs. J. Invest. Dermatol. 77:240-243.

56. Kurpakus, M. A., V. Quaranta, and J. C. R. Jones. 1991. Surface reloca-

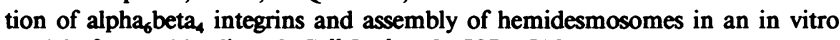
model of wound healing. J. Cell Biol. 115:1737-1750.

57. Zambruno, G., A. Cavani, V. Manca, M. L. Santantonio, and A. Giannetti. 1991. Integrin expression during wound healing in human skin transplanted onto nude mice. J. Invest. Dermatol. 96:1015-1015. (Abstr.)

58. Sonnenberg A., C. J. T. Linders, J. H. Daams, and S. J. Kennel. 1990. The $\alpha_{6} \beta_{1}$ (VLA-6) and $\alpha_{6} \beta_{4}$ protein complexes: tissue distribution and biochemical properties. J. Cell Sci. 96:207-217.

59. Carter, W. G., P. Kaur, S. G. Gil, P. J. Gahr, and E. A. Wayner. 1990. Distinct functions for integrins $\alpha_{3} \beta_{1}$ in focal adhesions and $\alpha_{6} \beta_{4}$ /bullous pemphigoid antigen in a new stable anchoring contact (SAC) of keratinocytes: relation to hemidesmosomes. J. Cell Biol. 111:3141-3154.

60. Bodary, S. C. M. A. Napier, and J. W. McLean. 1989. Expression of recombinant platelet glycoprotein IIbIIIa results in a functional fibrinogen-binding complex. J. Biol. Chem. 264:18859-18862.

61. Kaufmann, Y., E. Tseng, and T. A. Springer. 1991. Cloning of the murine lymphocyte function-associated molecule-1 $\alpha$-subunit and its expression in COS cells. J. Immunol. 147:369-374.

62. Baker, H., and A. M. Kligman. 1967. Technique for estimating turnover time of human stratum corneum. Arch. Dermatol. 95:408-411.

63. Halprin, K. M. 1972. Epidermal "turnover time"-A re-examination. $\mathrm{Br}$. J. Dermatol. 86:14-19.

64. Mansbridge, J. N., and A. M. Knapp. 1987. Changes in keratinocyte maturation during wound healing. J. Invest. Dermatol. 89:253-263.

65. Ralfkiaer, E., K. Thomsen, and G. L. Vejlsgaard. 1991. Expression of a cell adhesion protein (VLA- $\beta$ ) in normal and diseased skin. Br. J. Dermatol 124:527-532.

66. Nicholson, L. J., and F. M. Watt. 1991. Decreased expression of fibronectin and the $\alpha_{5} \beta_{1}$ integrin during terminal differentiation of human keratinocytes J. Cell Sci. 98:225-232.

67. Gottlieb, A. B. 1990. Immunologic mechanisms in psoriasis. $J$. Invest. Dermatol. 95:18S-19S.

68. McKenzie, R. C., and D. N. Sauder. 1990. Keratinocyte cytokines and growth factors. Dermatol. Clin. 8:649-661.

69. Nathan, C., and M. Sporn. 1991. Cytokines in context. J. Cell Biol. 113:981-986. 